\title{
Surfactant proteins in pediatric interstitial lung disease
}

\author{
Matthias Griese', Elke Lorenz', Meike Hengst', Andrea Schams', Traudl Wesselak', Daniela Rauch', Thomas Wittmann', \\ Valerie Kirchberger ${ }^{2}$, Amparo Escribano ${ }^{3}$, Thomas Schaible ${ }^{4}$, Winfried Baden ${ }^{5}$, Johannes Schulze ${ }^{6}$, Heiko Krude \\ Charalampos Aslanidis ${ }^{8}$, Nicolaus Schwerk ${ }^{9}$, Matthias Kappler ${ }^{1}$, Dominik Hart| ${ }^{10}$, Peter Lohse ${ }^{11}$ and Ralf Zarbock
}

BACKGROUND: Children's interstitial lung diseases (chILD) comprise a broad spectrum of diseases. Besides the genetically defined surfactant dysfunction disorders, most entities pathologically involve the alveolar surfactant region, possibly affecting the surfactant proteins SP-B and SP-C. Therefore, our objective was to determine the value of quantitation of SP-B and SP-C levels in bronchoalveolar lavage fluid (BALF) for the diagnosis of chILD.

METHODS: Levels of SP-B and SP-C in BALF from 302 children with chILD and in controls were quantified using western blotting. In a subset, single-nucleotide polymorphisms (SNPs) in the SFTPC promoter were genotyped by direct sequencing.

RESULTS: While a lack of dimeric SP-B was found only in the sole subject with hereditary SP-B deficiency, low or absent SP-C was observed not only in surfactant dysfunction disorders but also in patients with other diffuse parenchymal lung diseases pathogenetically related to the alveolar surfactant region. Genetic analysis of the SFTPC promoter showed association of a single SNP with SP-C level.

CONCLUSION: SP-B levels may be used for screening for SP-B deficiency, while low SP-C levels may point out diseases caused by mutations in TTF1, SFTPC, ABCA3, and likely in other genes involved in surfactant metabolism that remain to be identified. We conclude that measurement of levels of SP-B and SP-C was useful for the differential diagnosis of ChILD, and for the precise molecular diagnosis, sequencing of the genes is necessary.

nterstitial lung diseases occur at all ages and comprise a heterogeneous spectrum of different diseases which are mostly rare. Knowledge about their causes and pathomechanisms is scarce, and the therapeutic options for the affected patients are frequently very limited. In particular in children, the disease spectrum is even broader, with many diseases uniquely manifesting during infancy, prevalence being several times lower than that in adults (1), and the diseases occur in the environment of an immature immune system and a rapidly growing and developing lung $(2,3)$. Special effort in recent years has successfully delineated the framework necessary for the investigation of entities grouped as children's interstitial lung diseases (chILD) or pediatric diffuse parenchymal lung diseases (DPLD) (4). Genetically, mutations in SFTPB and SFTPC, as well as in other genes necessary for surfactant metabolism, e.g., ABCA3, TTF1, and CSFRA, lead to well-defined molecular diseases, the surfactant dysfunction disorders (5). Besides these entities, there exist several other diffuse parenchymal lung diseases that are pathogenetically related to the alveolar surfactant region (6). They have the same clinical and pathological presentation including the histologic pattern of chronic pneumonitis of infancy, nonspecific interstitial pneumonitis, desquamative interstitial pneumonitis, pulmonary alveolar proteinosis (PAP), and others (3); however, their genetic causes, if any, still remain undetermined. Such usually rare entities, together with additional diseases, primarily manifest during infancy (Table 1, groups A), whereas the other disorders manifest at all ages (Table 1, groups B).

Alveolar surfactant is a mixture of phospholipids and specific proteins which prevents expiratory collapse of the lungs and is indispensable for normal breathing. The hydrophobic surfactant proteins B (SP-B) and C (SP-C) are key components and when disturbed or lacking lead to dysfunctional surfactant (7-9). SP-B is encoded by a single gene (SFTPB) and is translated and processed in alveolar type II cells to a mature monomeric protein of about $8 \mathrm{kDa}$ which is secreted and active as a homodimer of $16 \mathrm{kDa}$ in the alveolar space (10). In addition, proSP-B may be produced by bronchiolar club cells (11). Lack of SP-B leads to severe respiratory distress, interstitial lung disease (7), and ultimately death if the patient is not transplanted. However, SP-B deficiency may be amenable to corrective treatment in the future (12). SP-C is a smaller peptide of about $4 \mathrm{kDa}$ and solely produced by alveolar type II cells by transcription of SFTPC. To a small extent, dimers or higher oligomers are formed (13). It is secreted together with the surfactant lipids from the lamellar bodies into the alveolar space $(5,14)$. Mutations of SFTPC lead to interstitial lung disease, manifesting mainly postnatally or during early infancy (15).

\footnotetext{
'Dr von Hauner Children's Hospital, German Center for Lung Research (DZL), University of Munich, Munich, Germany; ${ }^{2}$ Pediatric Pneumology, Charite, Berlin, Germany; ${ }^{3}$ Hospital Clinico Universitario, Unidad Neumologia Infantil, Valencia, Spain; ${ }^{4}$ Neonatology, University Children's Hospital, Mannheim, Germany; ${ }^{5}$ Pediatric Cardiology, University Children's Hospital, Tuebingen, Germany; ${ }^{6}$ Children's Hospital, Johann Wolfgang Goethe-University, Frankfurt, Germany; ${ }^{7}$ Pediatric Endocrinology, Charite, Berlin, Germany; ${ }^{8}$ Institute for Clinical Chemistry and Laboratory Medicine, University of Regensburg, Regensburg, Germany; ${ }^{9}$ Pediatric Pulmonology, Hannover Medical School, Hannover, Germany; ${ }^{10} \mathrm{Children's} \mathrm{Hospital} \mathrm{and} \mathrm{Interdisciplinary} \mathrm{Center} \mathrm{for} \mathrm{Infectious} \mathrm{Diseases,} \mathrm{University} \mathrm{of} \mathrm{Tuebingen,} \mathrm{Tuebingen,} \mathrm{Germany;}{ }^{11}$ Praxis für Humangenetik, CeGaT GmbH, Tübingen, Germany. Correspondence: Matthias Griese (matthias.griese@med.uni-muenchen.de)

Received 25 February 2015; accepted 22 June 2015; advance online publication 21 October 2015. doi:10.1038/pr.2015.173
} 
From the previous studies, we know that there are qualitative differences in the expression profiles of SP-B and SP-C in the bronchoalveolar lavage fluids (BALF) of such children (16). However, not much is known regarding the quantitative levels of these proteins. In particular, no studies have compared the full range of these diseases, to yield better estimates of variability and to examine the relative importance of biochemical determinations of their BALF levels. It has been shown that the levels of SP-C in patients with known mutations in SFTPB $(17,18), \operatorname{SFTPC}(19,20), A B C A 3(21)$, and TTF1 (22) are low. Thus, we hypothesized that SP-C might serve as a helpful screening tool for such and additional surfactant dysfunction disorders. In conjunction with measurement of SP-C levels and based on studies suggesting an association of some SFTPC promoter single-nucleotide polymorphisms (SNPs) with reduced transcription of SP-C in vitro (23), we also investigated if these and additional SNPs in the SFTPC promoter might regulate SP-C levels in BALF. Overall, the goal of this study was to determine the value of the quantitation of SP-B and SP-C levels in BALF for the diagnosis of chILD.

\section{RESULTS}

The spectrum of chILD diagnoses analyzed here represents the typical range of conditions found in larger studies (Table 1; Supplementary Table S1 online). There was a preponderance of male over female (1.6:1; Table 1), 77\% of the diseases

Table 1. Patient characteristics

\begin{tabular}{|c|c|c|c|c|c|}
\hline & $\begin{array}{l}\text { Category } \\
\text { code }\end{array}$ & $\begin{array}{l}\text { Number of } \\
\text { subjects }\end{array}$ & $\begin{array}{l}\text { Age at inclusion } \\
\text { (years) }^{\mathrm{a}}\end{array}$ & $\begin{array}{l}\text { Sex } \\
\mathrm{m} / \mathrm{f}\end{array}$ & $\begin{array}{l}\text { Death/ } \\
\text { alive }\end{array}$ \\
\hline \multicolumn{6}{|l|}{ Comparison groups (extension of abbreviation) } \\
\hline Bronchitis-normal cell differential & - & 69 & $4.90((2.18-9.38)$ & $43 / 26$ & $0 / 69$ \\
\hline Bronchitis-neutrophilic & - & 38 & $1.66(0.40-5.44)$ & $28 / 10$ & $1 / 37$ \\
\hline Deficient alveolarization & A2 & 9 & $0.32(0.13-0.74)$ & $5 / 4$ & $1 / 8$ \\
\hline BPD-cLDI (bronchopulmonary dysplasia-chronic lung disease of prematurity) & $\mathrm{A} 2$ & 25 & $0.32(0.12-0.61)$ & $17 / 8$ & $4 / 21$ \\
\hline CTI (chronic tachypnea of infancy) & A3 & 32 & $0.78(0.37-1.12)$ & $20 / 12$ & $0 / 32$ \\
\hline RDS 37-40 wk (unclear respiratory distress syndrome of the mature) ${ }^{c}$ & Ax & 19 & $0.08(0.03-0.16)$ & $13 / 6$ & $6 / 13$ \\
\hline $\begin{array}{l}A B C A 3 \text { - one (one variant of unclear significance in the } A B C A 3 \text { transporter gene } \\
\text { in a patient with respiratory symptoms and suspected interstitial lung disease) }\end{array}$ & A4 & 6 & $2.62(0.31-7.98)$ & $3 / 3$ & $1 / 5$ \\
\hline CPI (chronic pneumonitis of infancy) & A4 & 4 & $2.66(0.11-6.71)$ & $3 / 1$ & $1 / 3$ \\
\hline $\begin{array}{l}\text { Nxk2-1 defect (disease-causing mutation in the gene coding thyroid } \\
\text { transcription factor } 1 \text { ) }\end{array}$ & A4 & 2 & $9.98(0.27-19.7)$ & $2 / 0$ & $1 / 1$ \\
\hline NSIP (nonspecific interstitial pneumonitis) & A4 & 9 & $0.72(0.44-2.98)$ & $1 / 8$ & $3 / 6$ \\
\hline PAP (pulmonary alveolar proteinosis) ${ }^{d}$ & A4 & 5 & $2.76(0.97-9.99)$ & $1 / 4$ & $1 / 4$ \\
\hline Microlithiasis & A4 & 1 & 4.88 & $0 / 1$ & $0 / 1$ \\
\hline SP-B mutation (mutation in the gene encoding for surfactant protein B) & A4 & 1 & 0.00 & $0 / 1$ & $1 / 0$ \\
\hline $\mathrm{SP}-\mathrm{C}$ mutation (mutation in the gene encoding for surfactant protein $\mathrm{C}$ ) & A4 & 3 & $0.55(0.02-19.2)$ & $3 / 0$ & $0 / 3$ \\
\hline LIP & B5 & 2 & $8.42(0.05-16.8)$ & $0 / 2$ & $0 / 2$ \\
\hline Unclear nonneonate & $\mathrm{Bx}$ & 3 & $0.66(0.64-9.81)$ & $1 / 2$ & $3 / 0$ \\
\hline
\end{tabular}

FOXF1, Forkhead box F1; GM-CSF, granulocyte-macrophage colony-stimulating factor; LIP, lymphoid interstitial pneumonitis; PAP, pulmonary alveolar proteinosis.

¿Data are given as median and interquartile range. 'Histologically proven, one child survived, no FOXF1 analysis done as yet. 'The term "unclear" refers to the absence of a definite

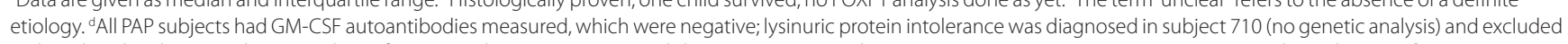
in the others by plasma and urine analysis of amino acids. GM-CSF receptor alpha sequencing was done in two instances; in one it was positive, as indicated in Supplementary Table $\mathbf{S 1}$ online. 
presented during infancy, and a mortality rate of $18 \%$ was observed (Table 1). BALF total protein was elevated in entities with inflammatory reactions, e.g., neutrophilic bronchitis and bronchopulmonary dysplasia-chronic lung disease of prematurity, and in those with alveolar proteinosis (Supplementary Figure S1 online). SP-B was predominantly identified as $16 \mathrm{kDa}$ dimers (Figure 1), which was about threefold to fourfold more abundant than the monomer (Supplementary Figure S2 online). Generally, the ratio of dimer to monomer did not vary significantly over the different diseases (not shown), as the overall concentration of SP-B was rather uniform except for PAP in which significantly elevated dimeric SP-B was observed. SP-B deficiency due to mutations in SFTPB was the only condition in which a lack of SP-B was found (Figure 1; Supplementary Figure S2 online).

SP-C monomers with a molecular weight of about $4 \mathrm{kDa}$ were the predominant forms of SP-C, representing about $50-70 \%$ of this protein in BALF (Figure 2), whereas SP-C aggregated to dimers was found in 30-50\% (Supplementary Figure S3 online). In contrast to SP-B, SP-C was either much more frequently present at low concentration or absent (20 of 302 samples, Table 2). This was observed in patients with diffuse developmental disorders (A1) and surfactant dysfunction disorders ( $A B C A 3, S P-B, S P-C$, and $N x k$ 2-1 mutations). SP-C was increased in children with chronic tachypnea of infancy (A3; commonly referred to as neuroendocrine cell hyperplasia of infancy in North America), nonspecific interstitial pneumonitis (A4), PAP (A4), and DPLDs with lung vessel structural abnormalities (B4) (Figure 2).

As the concentration of SP-B was relatively stable and appeared independent of the clinical conditions investigated except SP-B deficiency and PAP, we asked if the ratio of SP-C to SP-B could more reliably indicate a status of SP-C deficiency (Supplementary Figure S4 online). The lower quartile in healthy controls was 0.09 , suggesting SP-C deficiency at lower levels than the above ratio. However, the specificity of this limit was poor for DPLD, as several conditions with inflammation, and not necessarily with involvement of the alveolar space, also had levels below this threshold.

In a cohort of patients where we did not anticipate strong (mono-) genetic regulation of the SP-C level (Figure 3 ) and where both BALF and DNA were available, we investigated SP-C promoter SNPs for their ability to predict SP-C levels. Sequence variations in the promoter region that were observed more than once were included into the analysis. Among these patients, the frequency distribution of the SNPs did not differ between cases and controls, suggesting no selection advantage of these SNPs for DPLD (Supplementary Table S2 online). The SNP rs6557857 was found to be significantly associated with BALF levels of mature SP-C among all subjects and also among the patient cohort (Supplementary Table S3 online). The highest SP-C levels were observed for the AA genotype $(67.8$ vs. $120 \mathrm{ng} / \mathrm{ml}$ vs. $218 \mathrm{ng} / \mathrm{ml}$ for genotypes GG, GA, and AA, respectively; $P=0.03$ ). None of the other promoter

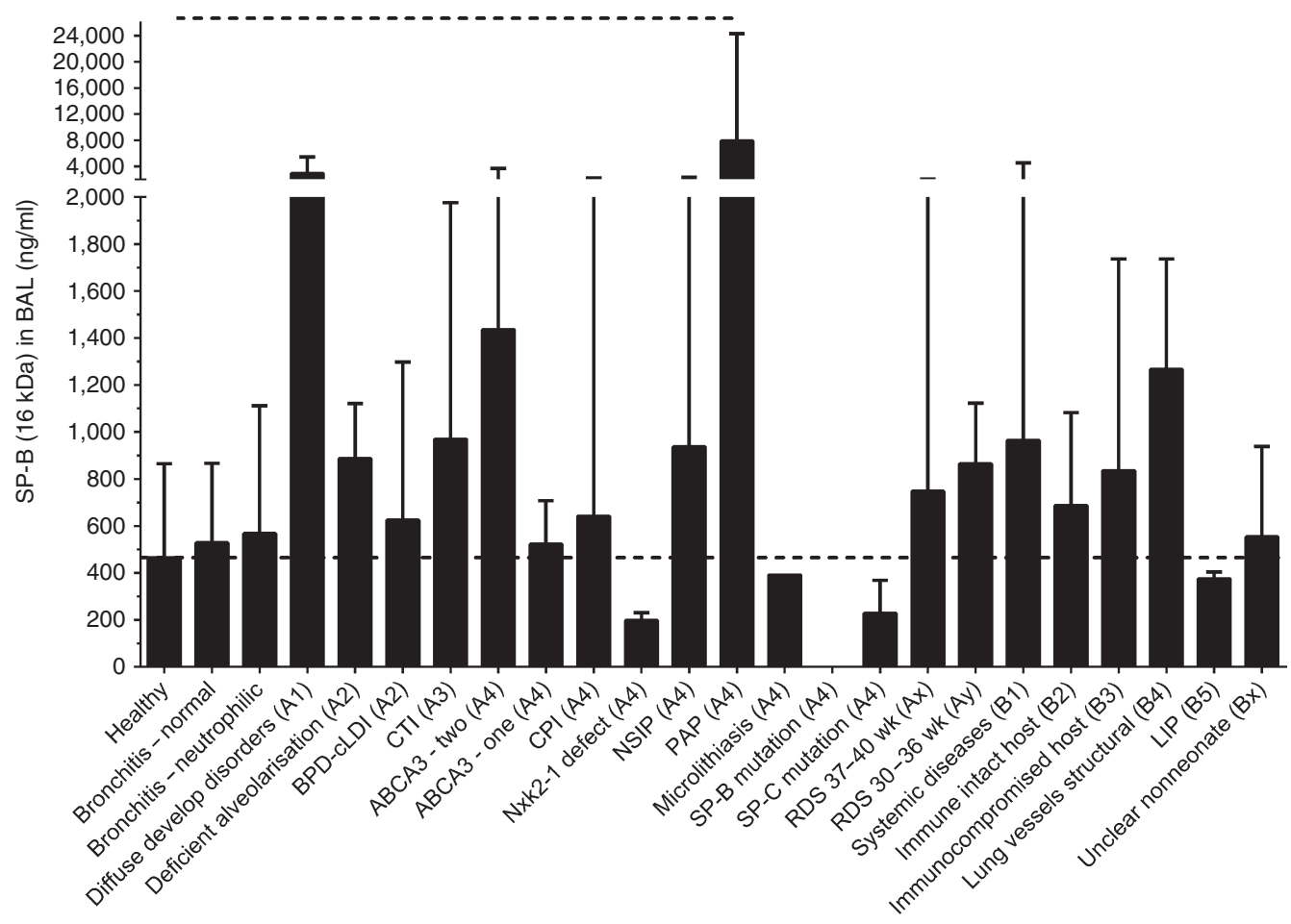

Figure 1. Concentration of surfactant protein B (SP-B) with a molecular weight of about $16 \mathrm{kDa}$ (mature SP-B dimer) in bronchoalveolar lavage fluid of subjects in the different disease categorizations. Data were analyzed by nonparametric ANOVA (overall $P=0.0019$ ), differences to healthy controls tested with Dunn's post hoc test are indicated by lines at the top of the figure (dashed $P<0.05$ ), and results are given as medians and interquartile range. The dashed line indicates the level of healthy subjects. For abbreviations and more details on age and number, see Table 1. 


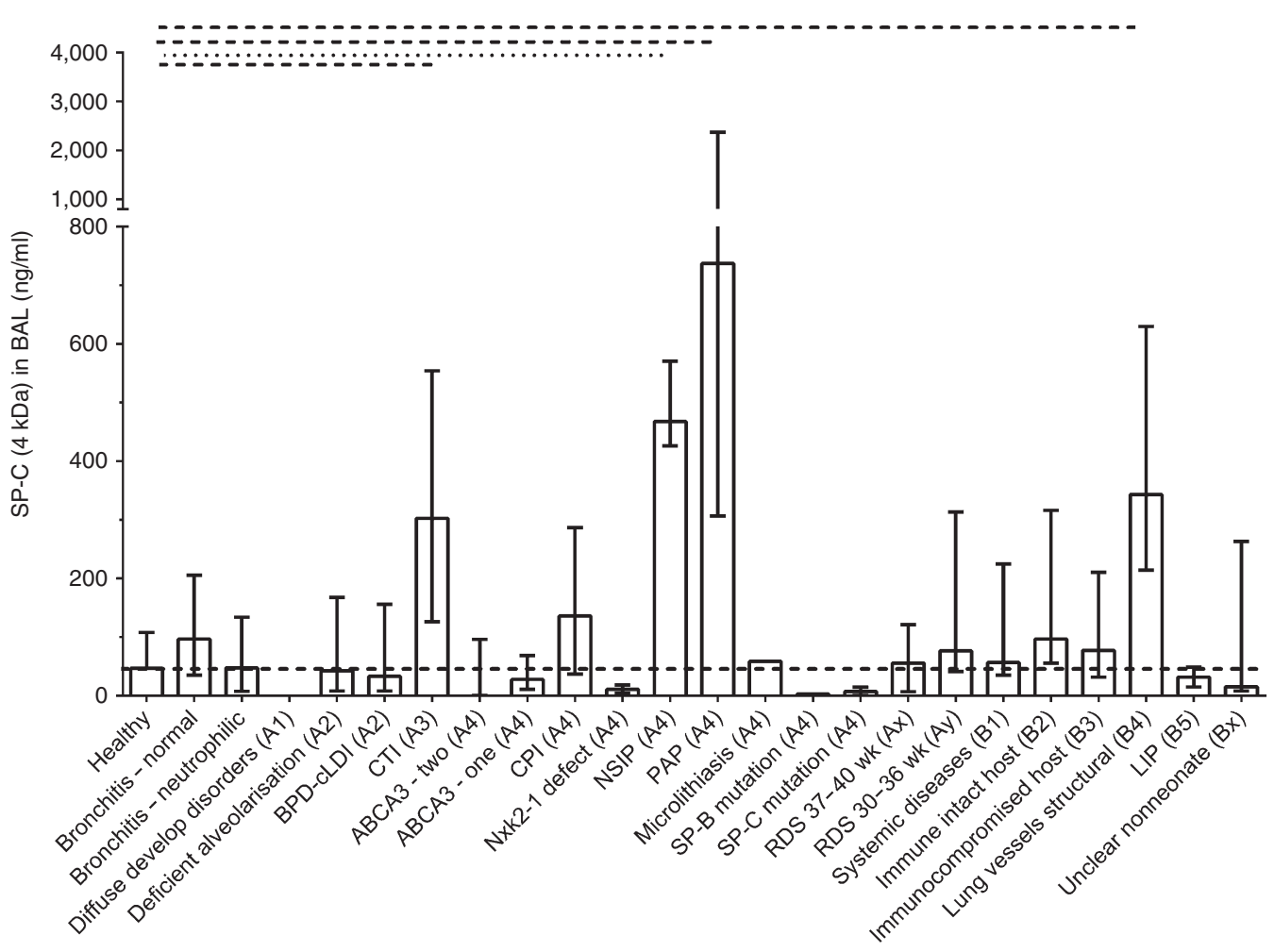

Figure 2. Concentration of surfactant protein $\mathrm{C}(\mathrm{SP}-\mathrm{C})$ with a molecular weight of about $4 \mathrm{kDa}$ (mature SP-C, monomer) in bronchoalveolar lavage fluid of subjects in the different disease categorizations. Data were analyzed by nonparametric ANOVA (overall ANOVA $P<0.0001$ ), differences to healthy controls tested with Dunn's post hoc test are indicated by lines at the top of the figure (dashed $P<0.05$, dotted $P<0.01$ ), and results are given as medians and interquartile range. The dashed line indicates the level of healthy subjects. For abbreviations and more details on age and number, see Table 1.

SNPs significantly determined BAL concentration of SP-C (Supplementary Table S3 online).

\section{DISCUSSION}

Here, we characterized the levels of SP-B and SP-C in BALF in a relatively large cohort of pediatric DPLD patients, in order to determine the diagnostic value of these hydrophobic surfactant proteins. To achieve this, we investigated a cohort of pediatric DPLD patients which was representative with respect to typical age range, mortality rate, and disease spectrum of individuals or small groups of rare to ultrarare diseases. The investigation of a larger and heterogeneous group of patients was important to overcome shortcomings of previous studies which only compared a single DPLD entity to a control group, making it difficult to judge on the specificity of testing and variation of levels over the disease spectrum.

SP-B, a dimer of $16 \mathrm{kDa}$, was detected easily in all cases investigated except for the single case of hereditary SP-B deficiency. Together with the finding of lacking SP-B in all other reported cases of this genetic disorder $(7,17,18,24-26)$ and the successful rescue of SP-B-deficient knockout mice (27), the analysis of BALF for SP-B concentration appears diagnostically helpful when pediatric DPLD potentially including this rare condition are investigated. In this context, it must be recommended to sample BAL before exogenous surfactant is applied, as the latter usually contains both SP-B and SP-C whose in vivo half-lives may be very long (28-30). For the precise diagnosis of SP-B deficiency, sequencing of the gene is necessary.

We were surprised by the wide range of SP-C levels found. As expected, low levels were observed in children with diseases involving the alveolar surfactant region; however, we also observed cases with low or absent SP-C in almost all other disease categories. A potential additional cause for low levels of SP-C was the presence of high relative neutrophil counts in BALF in such subjects (Table 2). Within this group of children with neutrophilic bronchitis, a weak negative correlation between SP-C level and percentage of neutrophils was found $(P=0.07 ; r=0.30 ; n=36)$. This was unexpected, as we did not observe such an effect in our previously studied cohort of patients with cystic fibrosis and significant airway inflammation (31). Potential explanations include compensatory upregulation of SP-C in such patients with lifelong neutrophilic inflammation (13), a more compartmented inflammation in cystic fibrosis compared to that in noncystic fibrosis bronchitis, protecting the alveolar space from proteolytic damage (32), or differential actions of cytokines or other factors secreted. To avoid false-negative or low levels, simultaneous determination of neutrophil count should be performed.

Of interest were those conditions with significantly elevated levels of SP-C. Such increases were already known for PAP $(33,34)$, but not for DPLD associated with lung vessel structural abnormalities or for nonspecific interstitial pneumonitis. In particular, infants with chronic tachypnea, a relatively frequent, but 
Table 2. Individual data of patients without SP-C of $4 \mathrm{kDa}$ in their BALF

\begin{tabular}{|c|c|c|c|c|c|c|c|}
\hline Number & Patient ID & Sex & $\begin{array}{l}\text { Disease } \\
\text { category }\end{array}$ & Diagnosis & $\begin{array}{l}\text { Patient } \\
\text { dead }\end{array}$ & $\begin{array}{l}\mathrm{SP}-\mathrm{C} 4 \mathrm{kDa} \\
(\mathrm{ng} / \mathrm{ml})\end{array}$ & $\begin{array}{l}\text { Neutrophils } \\
\text { (\%) }\end{array}$ \\
\hline 1 & 1178 & $\mathrm{~F}$ & A1 & $\begin{array}{l}\text { Diffuse develop disorders (alveolar capillary } \\
\text { dysplasia with misalignment of the pulmonary veins) }\end{array}$ & Yes & 0 & n.a. \\
\hline 3 & 701 & M & $\mathrm{A} 2$ & Deficient alveolarization (trisomy 21) & No & 0 & n.a. \\
\hline 4 & 1989 & M & A2 & Related to preterm birth (BPD-cLDI) & Yes & 0 & n.a. \\
\hline 6 & 2064 & M & A4 & SP-C mutation & No & 0 & 6 \\
\hline 7 & 1822 & $\mathrm{~F}$ & A4 & $\mathrm{ABCA} 3$ - two mutations & No & 0 & n.a. \\
\hline 8 & 1354 & M & A4 & ABCA3 - two mutations & Yes & 0 & n.a. \\
\hline 9 & 1479 & $\mathrm{~F}$ & A4 & $A B C A 3$ - one mutation & No & 0 & 36 \\
\hline 10 & 636 & M & A4 & $\mathrm{ABCA} 3$ - two mutations & Yes & 0 & n.a. \\
\hline 14 & 162 & $\mathrm{~F}$ & D & Bronchitis-neutrophilic & No & 0 & 80 \\
\hline 15 & 1171 & M & D & Bronchitis-neutrophilic & No & 0 & 50 \\
\hline 16 & 705 & M & D & Bronchitis-neutrophilic & No & 0 & 93 \\
\hline 17 & 1958 & M & D & Bronchitis-neutrophilic & No & 0 & 47 \\
\hline 18 & 1319 & M & D & Bronchitis-neutrophilic & No & 0 & 38 \\
\hline 19 & 1548 & M & D & Bronchitis-neutrophilic & No & 0 & 15 \\
\hline 20 & 416 & M & D & Bronchitis-neutrophilic & No & 0 & 80 \\
\hline
\end{tabular}

BALF, bronchoalveolar lavage fluid; n.a., not available; SP-C, surfactant protein C.

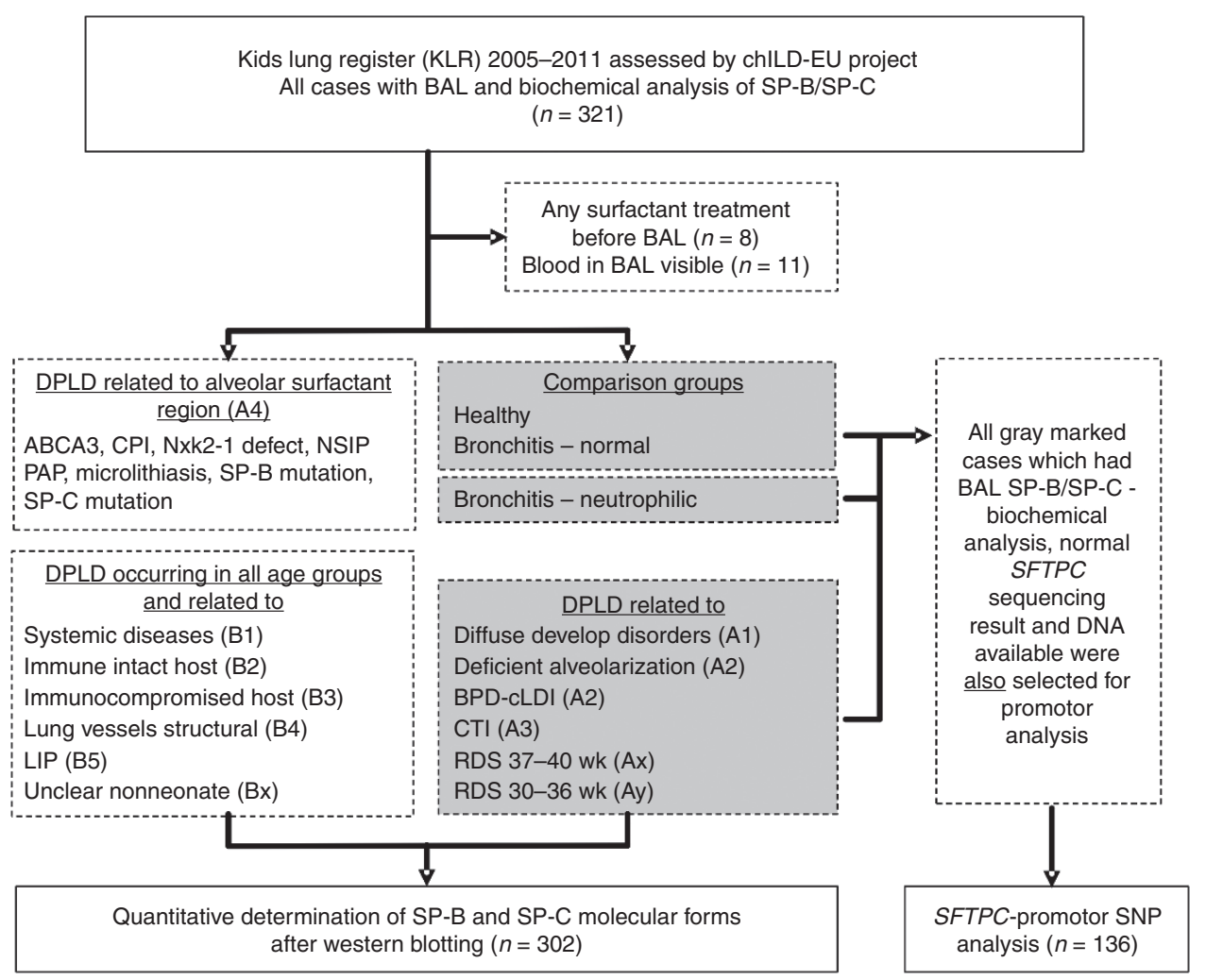

Figure 3. Flow chart of patient allocation. 
still unexplained, condition (3), had elevated SP-C levels. This may be helpful in differentiating the condition from surfactant dysfunction disorders with reduced levels and may complement serum measurements of KL-6 (35). The robustness of elevated SP-C in chronic tachypnea of infancy compared to controls and its potential causes need to be addressed in future studies.

Inspired by previous studies that had identified SNPs which lead to reduced expression of SP-C in vitro (23), we investigated if those and additional SNPs would predict a lower SP-C level in BALF. The frequencies of the SNPs reported by Wambach et al. were comparable with those we found in our study. However, numbers were too low to perform a statistical analysis of their impact on SP-C levels. Of note, the risk alleles that Wambach et al. reported were overrepresented in the patients with respiratory distress syndrome (RDS) among our cohort. Here, we show that another SFTPC promoter SNP, rs6557857, exerts influence on the SP-C level in BALF. Presence of the G allele either in hetero- or homozygous state was associated with lower SP-C levels compared to homozygous carriers of the A allele. The G allele occurred with a frequency of $40.9 \%$ in our cohort which is in accordance with the frequency reported by the 1000 genomes project for the European population (39.6\%). The mechanistic basis for this effect is currently unknown; in vitro studies will be needed to investigate this issue further. Nonetheless, our results show that SFTPC promoter SNPs may affect SP-C levels in vivo and should be considered in cases of SP-C deficiency without an obvious cause.

The prerequisite for reliable assessment of BALF levels of proteins with extraordinary features, i.e., extreme hydrophobicity or small size, is a reliable assay. Although labor intensive, western blotting with quantitative determination of proteins identified at defined molecular weights was a very sensitive and specific method, which was linear over a wide range of concentrations and had a high reproducibility (31). Here, we used the assay to address the question if determination of these proteins in BALF may be a helpful screening tool for suspected DPLD cases or not.

A shortcoming of this largest study of a disease marker in a pediatric cohort of DPDL is the still limited sample size, resulting in small number of subjects in many diagnostic categories. Additionally, more complete genetic testing, in particular in the group of children with unclear RDS, is desirable. These circumstances considerably limit the power of our study to detect differences between groups. To address this shortcoming, more patients and lavages need to be collected for several rare to ultrarare conditions in a standardized manner. To allow usage for comparison with additional cases, we made all individual values available in (Supplementary Table S1 online) In addition, the associated biosample repository is available for further scientific studies at the kids' lung register.

We conclude that quantitative determination of SP-B in BALF of children with suspected DPLD may be used as a tool to biochemically exclude a SP-B deficiency; for diagnosis of SP-B deficiency, sequencing of SFTPB is necessary. Determination of SP-C levels may point out the presence of mutations in TTF1, SFTPC, ABCA3, and likely other genes involved in surfactant metabolism. Moreover, our results support the view that genetic variation in the SFTPC promoter influences SP-C levels in BALF.

\section{METHODS}

\section{Patients and Bronchoalveolar Lavage}

All pediatric cases with suspected DPLD, in whom bronchoalveolar lavage fluid (BALF) was available, and healthy and disease comparison groups (total $n=321$ ), collected between 2005 and 2011, were assessed (Figure 3), and biochemical analysis of SP-B and SP-C was performed. DPLDs were carefully diagnosed and categorized according to the current diagnostic systems $(1,3,6,36)$ (Table 1 and Figure 3$)$. Neonates or children with severe RDS were labeled "unclear," after exclusion of common clinical causes, including infections, cardiac, metabolic, structural abnormalities, or neurologic causes of the respiratory distress. The diagnosis of "unclear RDS" was made on clinical and radiological grounds; in these cases, biopsies, autopsy, or molecular tests were not always done. The comparison groups were divided into children with normal differential cell counts in BALF (healthy, bronchitis-normal cell differential) and elevated neutrophils (bronchitis-neutrophilic). BALF was obtained by standard technique using 3 to $4 \mathrm{ml} / \mathrm{kg}$ body weight of warm $0.9 \% \mathrm{NaCl}$ instilled in portions of $1 \mathrm{ml} / \mathrm{kg}$. The recovered fluid was filtered through gauze, the first fraction was kept separately, the other fractions were pooled, cells were recovered for differential count, and supernatant used for biochemical analysis (37).

\section{Analysis of Total Protein and SP-B and SP-C Concentrations in BAL}

Total protein was measured by the method of Bradford. SP-B and SP-C were determined as described previously $(16,31)$. Briefly, SP-B and SP-C were separated on $10 \%$ Bis-Tris gels, identified by western blotting (using SP-C antibodies (generated in the rabbit against recombinant human SP-C, charge 22/96) and SP-B antibodies (generated in the rabbit against recombinant human SP-B, charge C 329); both gifts from Byk-Gulden, Konstanz, Germany) and quantified with the help of two standard runs on each gel (10 and $20 \mathrm{ng}$ of SP-B, 10 and $25 \mathrm{ng}$ of SP-C, using the Diana III chemiluminescence detection system and Advanced Image Data Analyzer software, version 4.04.032 (Raytest, Straubenhardt, Germany)) (Supplementary Figure S5 online). The assay for SP-B was linear between 1 and $40 \mathrm{ng}$, the one for SP-C between 3 and $80 \mathrm{ng}$. The inter-assay coefficient of variation was 10\% for SP-B and 19\% for SP-C.

\section{Genetic Analysis}

SFTPB and SFTPC were assessed according to clinical indication as described (31). Analysis of SFTPC promoter SNPs was performed in a total of 136 patients of whom DNA was available. This subset comprised cases belonging to the groups "healthy" and "bronchitisnormal number of neutrophils in BAL" $(n=56)$, "bronchitis-neutrophilic" ( $n=25)$, "DPLD due to deficient alveolarization" (A1, $n=3)$, "BPD-cLDI" (A2, $n=15)$, "chronic tachypnea of infancy" (A3, $n=$ 16), "RDS of the mature neonate" (RDS $37-40 \mathrm{wk}, A x, n=16)$, and "RDS of the almost mature neonate" (RDS 30-36 wk, Ay, $n=5$ ).

For SNP genotyping, genomic DNA was isolated from EDTA blood samples using the QIAamp DNA Blood Mini Kit (Qiagen, Hilden, Germany) and PCR amplified using AmplitaqGOLD polymerase (Life Technologies, Darmstadt, Germany). PCR products were purified with the MinElute 96 UF PCR Purification Kit (Qiagen). Primers used for PCR and sequencing reactions are given in Supplementary Table S4 online. Sequencing was performed by GATC Biotech AG (Konstanz, Germany). Sequences were aligned to the reference sequence (RefSeq accession NG_029334) using Mutation Surveyor 4.0 (SoftGenetics, State College, PA). ABCA3 and TTF1 were determined as described previously $(38,39)$.

\section{Statistical Analysis}

Frequency distributions of the analyzed SNPs were compared using the chi-square test. Comparisons of multiple groups were done using Kruskal-Wallis ANOVAs with Dunn's post hoc test. $P$ values of less than 0.05 were considered statistically significant. All tests were performed using GraphPad Prism 5.0 (GraphPad Software, La Jolla, CA). For transparency, recalculation, and further usage, several individual data are supplied in Supplementary Table S1 online. 


\section{Articles Griese et al.}

\section{Ethics Statement}

All participants and for children under $18 \mathrm{y}$ of age their legal representatives gave written informed consent to participate in the kids' lung register consultation and diagnosis program. The retrospective analysis of the data was approved by the institutional review board (EK 026-06). Prospective collection analysis of data was approved in the GOLD.net project (EK 257-10), and analysis was performed under the project FP7-305653-chILD-EU (EK 111-13).

\section{SUPPLEMENTARY MATERIAL}

Supplementary material is linked to the online version of the paper at http://www.nature.com/pr

\section{ACKNOWLEDGMENTS}

We thank the following external physicians for submitting lavage for surfactant diagnostics: Schwerk/Gappa/Rau (Hannover), Zielen/Schulze/Markus/ Gascon/Willasch/Wittekindt/Lieb/Brand (Frankfurt a. Main), Seidenberg/ Köster/Hartmann/Mahlert (Oldenburg), Körner-Rettberg/Nüßlein/Teig/ Gruber (Bochum), Zimmermann/Leis (Erlangen), Baden/Kumpf (Tübingen), Kopp/Urbanek (Freiburg), Escribano (ESP - Valencia), Riedel/Ahrens (Hamburg), Firnhaber/Singer (Hamburg), Hoppe/Rietschel/Hünseler/Welzing (Köln), Hebestreit/Silwedel/Wölfl/Kunzmann (Würzburg), Schaible (Mannheim), Pross/Kroll/Ocker (Stuttgart), Lau/Varnholt/Krude (Berlin), van Kaam/Slot/von der Thüsen (NL- Amsterdam), Werner (Münster), Kremers/ Stengel/Saur/Freihorst (Aalen), Rücker/Saadi/Armbruster (München), Kremens/Hanssler/ Große-Onnebrink (Essen), Barker/Wahn (Berlin), Lange/ Kriebel/Boschan (Göttingen), Aschmann/Rollow/Vogelberg (Dresden), Prenzel (Leipzig), Hermon, Weitzdoerfer, Amann (A- Wien), Richter (Hannover), Lange (Bonn), Lentze, Zeidler (Bonn), Luisetti/Campo (I- Pavia), Herterich, Engelhardt (Landshut), Krause (Kiel), Kemen (Hamburg), Ahrens (Darmstadt), Hanff/Manzke (Neubrandenburg), Pöschl/Bögershausen (Heidelberg), Kühr/ Bosch (Karlsruhe), Rau (Ravensburg), Störing/Roth (Berlin), Aslanidis (Regensburg), Hampel (Regensburg), Barikbin (Berlin), Hammer (Basel), Briassoulis (G- Heraklion), Poplawska (Ludwigshafen), Hülskamp (Münster), Pickert (Heilbronn), Bürger (Traunstein), Gortner (Homburg), Kopp/Ahrens (Lübeck), Nährlich (Giessen), Hubrich (Datteln), Donato (F- Strassbourg), Pin (F- Grenoble), Schirmer-Zimmermann (Nürnberg), Anani (Nürnberg), Gröbner (A- Linz), Laux (Hamburg), Romano (F- Paris), Mildenberger (Mainz), Lasch (Bremen), Kitz (Frankfurt a. Main), Weckelmann (Wuppertal), Renner (Neuburg/Donau), Schröder (Lüneburg), Fuchs (Ulm), Casaulta (CH- Bern), Schuster (Düsseldorf), Andree (Krefeld), Boelke (Villingen-Schwenningen), Braun (Erfurt), Weis (Koblenz), Reitz (Berlin), Ollerieth (A-Wien), and Rubens (Kaufbeuren).

This article contains parts of the thesis of Elke Lorenz.

\section{STATEMENT OF FINANCIAL SUPPORT}

The work of M.G. was supported by the German Research Council (Bonn Germany), the Federal Ministry of Education and Research (Bonn, Germany), the Seventh Framework Programme by the European Commission, FP7-305653-chILD-EU (Brussels, Belgium), and the Else Kröner-FreseniusStiftung (Bad Homburg, Germany).

Disclosure: None declared.

\section{REFERENCES}

1. Griese M, Haug M, Brasch F, et al. Incidence and classification of pediatric diffuse parenchymal lung diseases in Germany. Orphanet J Rare Dis 2009;4:26.

2. Clement A; ERS Task Force. Task force on chronic interstitial lung disease in immunocompetent children. Eur Respir J 2004;24:686-97.

3. Kurland G, Deterding RR, Hagood JS, et al.; American Thoracic Society Committee on Childhood Interstitial Lung Disease (chILD) and the chILD Research Network. An official American Thoracic Society clinical practice guideline: classification, evaluation, and management of childhood interstitial lung disease in infancy. Am J Respir Crit Care Med 2013;188:376-94.

4. Bush A, Anthony G, Barbato A, et al.; ch-ILD collaborators. Research in progress: put the orphanage out of business. Thorax 2013;68:971-3.

5. Hamvas A. Evaluation and management of inherited disorders of surfactant metabolism. Chin Med J (Engl) 2010;123:2943-7.

6. Deutsch GH, Young LR, Deterding RR, et al.; Pathology Cooperative Group; ChILD Research Co-operative. Diffuse lung disease in young children: application of a novel classification scheme. Am J Respir Crit Care Med 2007;176:1120-8.

7. Nogee LM, de Mello DE, Dehner LP, Colten HR. Brief report: deficiency of pulmonary surfactant protein B in congenital alveolar proteinosis. N Engl J Med 1993;328:406-10.

8. Nogee LM, Dunbar AE 3rd, Wert SE, Askin F, Hamvas A, Whitsett JA. A mutation in the surfactant protein $\mathrm{C}$ gene associated with familial interstitial lung disease. N Engl J Med 2001;344:573-9.

9. Weaver TE, Conkright JJ. Function of surfactant proteins B and C. Annu Rev Physiol 2001;63:555-78.

10. Nogee LM. Genetics of the hydrophobic surfactant proteins. Biochim Biophys Acta 1998;1408:323-33.

11. Khoor A, Stahlman MT, Gray ME, Whitsett JA. Temporal-spatial distribution of SP-B and SP-C proteins and mRNAs in developing respiratory epithelium of human lung. J Histochem Cytochem 1994;42:1187-99.

12. Kormann MS, Hasenpusch G, Aneja MK, et al. Expression of therapeutic proteins after delivery of chemically modified mRNA in mice. Nat Biotechnol 2011;29:154-7.

13. Tafel O, Latzin P, Paul K, Winter T, Woischnik M, Griese M. Surfactant proteins SP-B and SP-C and their precursors in bronchoalveolar lavages from children with acute and chronic inflammatory airway disease. BMC Pulm Med 2008;8:6.

14. Beers MF, Fisher AB. Surfactant protein C: a review of its unique properties and metabolism. Am J Physiol 1992;263:L151-60.

15. Kröner C, Reu S, Teusch V, et al. Genotype alone does not predict the clinical course of SFTPC deficiency in paediatric patients. Eur Respir J 2015;46:197-206.

16. Griese M, Schumacher S, Tredano M, et al. Expression profiles of hydrophobic surfactant proteins in children with diffuse chronic lung disease. Respir Res 2005;6:80.

17. Tredano $M$, van Elburg RM, Kaspers AG, et al. Compound SFTPB 1549C-> GAA (121ins2) and 457delC heterozygosity in severe congenital lung disease and surfactant protein B (SP-B) deficiency. Hum Mutat 1999;14:502-9.

18. Tredano M, Griese M, de Blic J, et al. Analysis of 40 sporadic or familial neonatal and pediatric cases with severe unexplained respiratory distress: relationship to SFTPB. Am J Med Genet A 2003;119A:324-39.

19. Thouvenin G, Abou Taam R, Flamein F, et al. Characteristics of disorders associated with genetic mutations of surfactant protein C. Arch Dis Child 2010;95:449-54.

20. Tredano M, Griese M, Brasch F, et al. Mutation of SFTPC in infantile pulmonary alveolar proteinosis with or without fibrosing lung disease. Am J Med Genet A 2004;126A:18-26.

21. Flamein F, Riffault L, Muselet-Charlier C, et al. Molecular and cellular characteristics of $\mathrm{ABCA} 3$ mutations associated with diffuse parenchymal lung diseases in children. Hum Mol Genet 2012;21:765-75.

22. Kleinlein B, Griese M, Liebisch G, et al. Fatal neonatal respiratory failure in an infant with congenital hypothyroidism due to haploinsufficiency of the NKX2-1 gene: alteration of pulmonary surfactant homeostasis. Arch Dis Child Fetal Neonatal Ed 2011;96:F453-6.

23. Wambach JA, Yang P, Wegner DJ, et al. Surfactant protein-C promoter variants associated with neonatal respiratory distress syndrome reduce transcription. Pediatr Res 2010;68:216-20.

24. Schuerman FA, Griese M, Gille JP, Brasch F, Noorduyn LA, van Kaam AH. Surfactant protein B deficiency caused by a novel mutation involving multiple exons of the SP-B gene. Eur J Med Res 2008;13:281-6.

25. Dunbar AE 3rd, Wert SE, Ikegami M, et al. Prolonged survival in hereditary surfactant protein B (SP-B) deficiency associated with a novel splicing mutation. Pediatr Res 2000;48:275-82.

26. Ballard PL, Nogee LM, Beers MF, et al. Partial deficiency of surfactant protein $\mathrm{B}$ in an infant with chronic lung disease. Pediatrics 1995;96:1046-52.

27. Akinbi HT, Breslin JS, Ikegami M, et al. Rescue of SP-B knockout mice with a truncated SP-B proprotein. Function of the C-terminal propeptide. J Biol Chem 1997;272:9640-7.

28. Simonato M, Baritussio A, Pioselli B, et al. Surfactant protein C metabolism in human infants and adult patients by stable isotope tracer and mass spectrometry. Anal Bioanal Chem 2014;406:6225-33. 
29. Simonato M, Baritussio A, Vedovelli L, Lamonica G, Carnielli VP, Cogo PE. Surfactant protein B amount and kinetics in newborn infants: an optimized procedure. J Mass Spectrom 2012;47:1415-9.

30. Griese M, Dietrich P, Reinhardt D. Pharmacokinetics of bovine surfactant in neonatal respiratory distress syndrome. Am J Respir Crit Care Med 1995;152:1050-4.

31. Griese M, Essl R, Schmidt R, et al.; BEAT Study Group. Pulmonary surfactant, lung function, and endobronchial inflammation in cystic fibrosis. Am J Respir Crit Care Med 2004;170:1000-5.

32. Griese M, Felber J, Reiter K, et al. Airway inflammation in children with tracheostomy. Pediatr Pulmonol 2004;37:356-61.

33. Paschen C, Reiter K, Stanzel F, Teschler H, Griese M. Therapeutic lung lavages in children and adults. Respir Res 2005;6:138.

34. Brasch F, Birzele J, Ochs M, et al. Surfactant proteins in pulmonary alveolar proteinosis in adults. Eur Respir J 2004;24:426-35.
35. Doan ML, Elidemir O, Dishop MK, et al. Serum KL-6 differentiates neuroendocrine cell hyperplasia of infancy from the inborn errors of surfactant metabolism. Thorax 2009;64:677-81.

36. Rice A, Tran-Dang MA, Bush A, Nicholson AG. Diffuse lung disease in infancy and childhood: expanding the chILD classification. Histopathology 2013;63:743-55.

37. Griese M. Pulmonary surfactant in health and human lung diseases: state of the art. Eur Respir J 1999;13:1455-76.

38. Brasch F, Schimanski S, Mühlfeld C, et al. Alteration of the pulmonary surfactant system in full-term infants with hereditary ABCA3 deficiency. Am J Respir Crit Care Med 2006;174:571-80.

39. Thorwarth A, Schnittert-Hübener S, Schrumpf P, et al. Comprehensive genotyping and clinical characterisation reveal 27 novel NKX2-1 mutations and expand the phenotypic spectrum. J Med Genet 2014;51: 375-87. 